\title{
Optimal Policy for Non-Instantaneous Decaying Inventory Model with Learning Effect and Partial Shortages
}

\author{
Anchal Agarwal \\ Centre for mathematical \\ Sciences \\ Banasthali University, \\ Rajasthan
}

\author{
Isha Sangal \\ Centre for Mathematical \\ Sciences \\ Banasthali University, \\ Rajasthan
}

\author{
S. R. Singh \\ Department of \\ Mathematics \\ C.C.S University \\ Meerut
}

\begin{abstract}
Deterioration of goods and learning is a realistic phenomenon in daily life. Therefore maintaining the stock of decaying items becomes an important factor for decision makers. In this study deterioration rate follows the Weibull distribution and holding cost is gradually decreases, therefore learning effect is incorporated on holding cost. Many researchers generally assumed that the shortages are either completely backlogged or lost. But in this paper shortage is allowed and partial backlogged. The backlogging rate is taken as exponential function of time. Numerical examples are provided to further illustrate the model. Sensitivity analysis has been carried out to analyze the impact of change in various parameters. The aim of this model is to minimize the total cost.
\end{abstract}

\section{Keywords}

Inventory, Non-instantaneous deterioration, Time dependent demand rate, Learning, Partial backlogging

\section{INTRODUCTION}

In most of the inventory models for deteriorating items, it is assumed that deterioration starts as soon as the retailer receives the inventory. During that period, there is no occurrence of deterioration. This phenomenon is commonly referred as non-instantaneous deterioration.

Ghare and Schrader [1963] addressed an EOQ model with constant rate of deterioration. Covert and Philip [1973] extended this model by considering variable rate of deterioration. The related works are found in (Nahmias [1982], Raafat [1991], Hariga [1996], Goyal and Giri [2001],). A non-instantaneous deteriorating items inventory model with stock dependent demand was developed by Wu et al. [2006]. Mishra et al. [2011] formulated the model for deterministic perishable items with variable type demand rate under infinite time horizon and constant deterioration. The effect of preservation technology investment on a noninstantaneous deteriorating inventory model was developed by Dye [2013]. Jaggi [2014] established a non-instantaneous deteriorating Items inventory model with price dependent demand and time-varying holding cost.

Many times customers would like to wait for backlogging during the shortage period but the others would not. Chang and Dye [1999] considered an EOQ model for deteriorating items with time varying demand and partial backlogging.
They were the first to give a definition for time dependent partial backlogging rate. Chern et al. [2008] developed an inventory model with inflation by assuming that the demand function is fluctuating. Sana [2010] developed lot size inventory model with time varying deterioration and partial backlogging. Widyadana et al. [2011] presented an economic order quantity model for deteriorating items and planned backorder level. An EOQ inventory model with time dependent demand and shortages was proposed by Singh et al. [2010], Agarwal and Singh [2013]. Shukla et al. [2013], Khanra et al. [2013] , Sarkar and Moon [2014] , Anchal et al. [2016] have studied the inventory model with partially backlogged shortages.

The learning phenomena introduced by Wright [1936] who suggested the power function, known as the learning curve (LC).Jordan [1958] analyzed that how to use the learning curve. The effect of learning on optimal lot determination, single product case was discussed by Adler and Nanda [1974]. Yelle [1979] analyzed the learning curve: historical review and comprehensive survey. The production lot sizing under learning effect was proposed by Fisk and Ballou [1985]. Balkhi [2003] enhanced the effect of learning on the optimal production lot size for deteriorating and partially backordered items with time varying demand and deterioration rate. Kumar et al. [2013] established a learning effect on an inventory model with two-level storage and partial backlogging under inflation. Jaber et al. [2008] examined an economic production quantity model for items with imperfect quality subject to learning effects. Yadav et al. [2013] enhanced an inventory model with learning effect and imprecise market demand under screening error. Singh et al. [2013] created an imperfect quality items with learning and inflation under two limited storage capacity. The cost of inventory model engaged in repetitive operations decrease due to the learning effect. Sangal et al. [2014] elaborated a fuzzy environment inventory model with partial backlogging under learning effect.

In this paper, the focus will be on commodities like fruits, medicines, electronic components etc. which either deteriorate or obsolete over a period of time. This is one of the factors that conclude the overall holding cost. An unfulfilled demand is an important factor in inventory theory. Therefore we developed a decaying inventory model with time dependent demand, learning effects under partial backlogging by which due to learning process we will get that our total cost of the model has reduced. 


\section{ASSUMPTIONS AND NOMENCLATURES}

\subsection{Assumptions}

We need the following assumptions for developing mathematical model

1. Demand rate is time dependent.

2. Shortages of goods are partially lost sale. The backlogging rate is $\delta(t)=e^{-\delta(T-t)}$, where $\delta$ is the backlogging parameter

3. The time to the deterioration of the product is distributed as Weibull.

4. Holding cost follows the learning curve.

5. There is no replenishment or repair of deteriorated items takes place in a given cycle.

\subsection{Notation}

The following notation is used to develop the mathematical model

- $\theta(t)=\alpha \beta t^{\beta-1}$ : two parameter Weibull deterioration

- $\mathrm{D}(\mathrm{t})=\left(a+b t+c t^{2}\right),:$ quadratic demand rate where $a>b, a>c$

- $\quad H(n)=\left(h_{0}+\frac{h_{1}}{n^{\mu}}\right)$ : learning coefficient holding $\operatorname{cost}$

- $\mathrm{C}_{0}$ : ordering cost

- $C_{D}:$ deterioration cost

- $C_{S}:$ shortage cost

- $C_{L}:$ lost sales cost

- $\delta$ : backlogging parameter

- $T C\left(t_{1}, T\right)$ : total cost of the inventory system

\section{DESCRIPTION OF MATHEMATICAL MODEL}

As the deterioration of product is life time, so initially, the units do not spoilage for some period and after that the deterioration starts. In the period $\left(0, t_{d}\right)$ the inventory level gradually depletes due to demand only but during the interval $\left(t_{d}, t_{1}\right)$ the inventory stock further decreases due to combined effect of demand and deterioration. At $t_{1}$ the inventory level dropping zero \& shortage are allowed in the duration $\left(t_{1}, T\right)$, which is partially backlogged. As depict above, the inventory levels are governed by the following differential equations: $\begin{array}{ll}\frac{d I_{1}(t)}{d t}=-\left(a+b t+c t^{2}\right), & 0 \leq t \leq t_{d} \\ \frac{d I_{2}(t)}{d t}+\alpha \beta t^{\beta-1} I(t)=-\left(a+b t+c t^{2}\right), & t_{d} \leq t \leq t_{1}\end{array}$

$\frac{d I_{3}(t)}{d t}=-e^{-\delta(T-t)}\left(a+b t+c t^{2}\right), \quad t_{1} \leq t \leq T$

With boundary conditions

$$
I_{1}(0)=I_{\text {ma.x. }}, I_{2}\left(t_{1}\right)=0 \& I_{3}\left(t_{1}\right)=0
$$

Solutions of these equations are

$$
\begin{aligned}
& I_{1}(t)=\left[I_{\max .}-\left(a t+\frac{b t^{2}}{2}+\frac{c t^{3}}{3}\right)\right] \\
& I_{2}(t)=\left[a\left(t_{1}-t\right)+\frac{b}{2}\left(t_{1}^{2}-t^{2}\right)+\frac{c}{3}\left(t_{1}^{3}-t^{3}\right)+\frac{a \alpha}{\beta+1}\left(t_{1}^{\beta+1}-t^{\beta} t_{1}(\beta+1)+\beta t^{\beta+1}\right)\right. \\
& \left.+\frac{b \alpha}{2(\beta+2)}\left(2 t_{1}^{\beta+2}-t^{\beta} t_{1}^{2}(\beta+2)+\beta t^{\beta+2}\right)+\frac{c \alpha}{3(\beta+3)}\left(3 t_{1}^{\beta+3}-t_{1}^{3} t^{\beta}(\beta+3)+\beta t^{\beta+3}\right)\right]
\end{aligned}
$$

$$
\begin{aligned}
& I_{3}(t)=e^{-\delta T}\left[\frac{a}{\delta}\left(e^{\delta t_{1}}-e^{\delta t}\right)+\frac{b}{\delta}\left(t_{1} e^{\delta t_{1}}-t e^{\delta t}\right)+\frac{b}{\delta^{2}}\left(e^{\delta t}-e^{\delta t_{1}}\right)+\right. \\
& \left.\frac{c}{\delta}\left(t_{1}^{2} e^{\delta t_{1}}-t^{2} e^{\delta t}\right)+\frac{2 c}{\delta^{2}}\left(t e^{\delta t}-t_{1} e^{\delta t_{1}}\right)+\frac{2 c}{\delta^{3}}\left(e^{\delta t_{1}}-e^{\delta t}\right)\right]
\end{aligned}
$$

Considering the continuity at $t=t_{d}$ it follows from equation (3.5) \& (3.6) such that $I_{1}\left(t_{d}\right)=I_{2}\left(t_{d}\right)$

We get

$$
\begin{aligned}
& I_{\text {max. }}=\left[a t_{1}+\frac{b}{2} t_{1}^{2}+\frac{c}{3} t_{1}^{3}+\frac{a \alpha}{\beta+1}\left(t_{1}^{\beta+1}-t_{d}^{\beta} t_{1}(\beta+1)+\beta t_{d}^{\beta+1}\right)+\frac{b \alpha}{2(\beta+2)}\right. \\
& \left.\left(2 t_{1}^{\beta+2}-t_{d}^{\beta} t_{1}^{2}(\beta+2)+\beta t_{d}^{\beta+2}\right)+\frac{c \alpha}{3(\beta+3)}\left(3 t_{1}^{\beta+3}-t_{1}^{3} t_{d}^{\beta}(\beta+3)+\beta t_{d}^{(\beta+3)}\right)\right]
\end{aligned}
$$

Using equation (3.8) in equation (3.5) we get

$$
\begin{aligned}
& I_{1}(t)=\left[a\left(t_{1}-t\right)+\frac{b}{2}\left(t_{1}^{2}-t^{2}\right)+\frac{c}{3}\left(t_{1}^{3}-t^{3}\right)+\frac{a \alpha}{\beta+1}\left(t_{1}^{\beta+1}-t_{d}^{\beta} t_{1}(\beta+1)+\beta t_{d}^{\beta+1}\right)+\right. \\
& \left.+\frac{b \alpha}{2(\beta+2)}\left(2 t_{1}^{\beta+2}-t_{d}^{\beta} t_{1}^{2}(\beta+2)+\beta t_{d}^{\beta+2}\right)+\frac{c \alpha}{3(\beta+3)}\left(3 t_{1}^{\beta+3}-t_{1}^{3} t_{d}^{\beta}(\beta+3)+\beta t_{d}^{(\beta+3)}\right)\right]
\end{aligned}
$$

Based on the assumptions of the model consider the following elements: 


\subsection{Ordering Cost}

$$
\mathrm{OC}=\mathrm{C}_{0}
$$

\subsection{Deterioration Cost}

$$
D C=C_{D} \int_{t_{d}}^{t_{1}} \theta(t) I_{2}(t) d t
$$

\subsection{Holding Cost}

$H C=\left(h_{0}+\frac{h_{1}}{n^{\mu}}\right)\left[\int_{0}^{t_{d}} I_{1}(t) d t+\int_{t_{d}}^{t_{1}} I_{2}(t) d t\right]$

\subsection{Shortage Cost}

$$
S C=C_{S} \int_{t_{1}}^{T}-I_{3}(t) d t
$$

\subsection{Lost Sales Cost}

$L S C=C_{L} \int_{t_{1}}^{T}\left(1-e^{-\delta(T-t)}\right)\left(a+b t+c t^{2}\right) d t$

\subsection{Total average cost of the system}

$T C\left(t_{1}, T\right)=\frac{1}{T}[O C+D C+H C+S C+L S C]$

\section{OPTIMALITY}

The total values of $t_{1}$ and $T$ which minimize the total cost can be solved by differentiating equation (3.15) with respect to $t_{1}$ and $\mathrm{T}$ and equate to zero

$$
\frac{\partial T C\left(t_{1}, T\right)}{\partial t_{1}}=0, \frac{\partial T C\left(t_{1}, T\right)}{\partial T}=0
$$

The sufficient conditions for minimizing $T C\left(t_{1}, T\right)$ using the Hessian matrix $\mathrm{H}$, which is the matrix of second order partial derivatives, are

$$
\begin{aligned}
& H=\left[\begin{array}{ll}
\frac{\partial^{2} T C\left(t_{1}, T\right)}{\partial t_{1}^{2}} & \frac{\partial^{2} T C\left(t_{1}, T\right)}{\partial t_{1} \partial T} \\
\frac{\partial^{2} T C\left(t_{1}, T\right)}{\partial t_{1} \partial T} & \frac{\partial^{2} T C\left(t_{1}, T\right)}{\partial T^{2}}
\end{array}\right] \\
& H_{1}=\frac{\partial^{2} T C\left(t_{1}, T\right)}{\partial t_{1}^{2}}>0 \\
& H_{2}=\left|\begin{array}{ll}
\frac{\partial^{2} T C\left(t_{1}, T\right)}{\partial t_{1}^{2}} & \frac{\partial^{2} T C\left(t_{1}, T\right)}{\partial t_{1} \partial T} \\
\frac{\partial^{2} T C\left(t_{1}, T\right)}{\partial t_{1} \partial T} & \frac{\partial^{2} T C\left(t_{1}, T\right)}{\partial T^{2}}
\end{array}\right|>0
\end{aligned}
$$

Where $H_{1}$ and $H_{2}$ are the minors of the Hessian matrix $\mathrm{H}$. Using these optimal values of $t_{1}$ and $\mathrm{T}$, the minimum total cost can be obtained.

\section{NUMERICAL EXAMPLE AND SENSITIVITY ANALYSIS}

5.1 Numerical Example

We have considered the following data given in appropriate units

$C_{0}=200, \delta=0.8, h_{0}=2.5, \beta=2, a=200, \alpha=0.04, t_{d}=0.02$,

$C_{D}=1.9, b=0.6, n=1, h_{1}=5, C_{S}=2, \mu=0.1, c=0.01, C_{L}=1.5$

Then we get optimal values of $t_{1}=0.223859, \mathrm{~T}=$ 0.994437 and total cost $T C\left(t_{1}, T\right)=$ Rs. 337.497.

\subsection{Sensitivity Analysis}

We examined the sensitivity analysis of the optimal solution

Table- (1): Effect of number of shipments (n) on optimal solution

\begin{tabular}{|c|c|c|c|}
\hline $\mathrm{n}$ & $t_{1}$ & $\mathrm{~T}$ & $T C\left(t_{1}, T\right)$ \\
\hline 1 & 0.223859 & 0.994437 & 337.497 \\
\hline 2 & 0.233025 & 0.994249 & 335.738 \\
\hline 3 & 0.238428 & 0.994205 & 334.701 \\
\hline 4 & 0.242278 & 0.994204 & 333.962 \\
\hline 5 & 0.245271 & 0.994220 & 333.387 \\
\hline 6 & 0.247722 & 0.994244 & 332.917 \\
\hline 7 & 0.249797 & 0.994272 & 332.518 \\
\hline 8 & 0.251596 & 0.994302 & 332.173 \\
\hline 9 & 0.253185 & 0.994333 & 331.868 \\
\hline 10 & 0.254607 & 0.994364 & 331.594 \\
\hline
\end{tabular}

Table- (2): Effect of demand parameter (a) on optimal solution

\begin{tabular}{|c|c|c|c|}
\hline $\mathrm{a}$ & $t_{1}$ & $\mathrm{~T}$ & $T C\left(t_{1}, T\right)$ \\
\hline 210 & 0.217388 & 0.93771 & 344.006 \\
\hline 220 & 0.21115 & 0.886766 & 349.935 \\
\hline 230 & 0.205126 & 0.840516 & 355.304 \\
\hline 240 & 0.199301 & 0.798146 & 360.13 \\
\hline
\end{tabular}


Table- (3): Effect of deterioration cost parameter $\left(C_{D}\right)$ on optimal solution

\begin{tabular}{|c|c|c|c|}
\hline$C_{D}$ & $t_{1}$ & $\mathrm{~T}$ & $T C\left(t_{1}, T\right)$ \\
\hline 2 & 0.223834 & 0.99443 & 337.500 \\
\hline 2.1 & 0.223810 & 0.994422 & 337.503 \\
\hline 2.2 & 0.223786 & 0.994415 & 337.506 \\
\hline 2.3 & 0.223762 & 0.994408 & 337.509 \\
\hline
\end{tabular}

Table- (4): Effect of scale parameter $(\alpha)$ on optimal solution

\begin{tabular}{|c|c|c|c|}
\hline$\alpha$ & $t_{1}$ & $\mathrm{~T}$ & $T C\left(t_{1}, T\right)$ \\
\hline 0.05 & 0.223674 & 0.994367 & 337.518 \\
\hline 0.06 & 0.223490 & 0.994297 & 337.539 \\
\hline 0.07 & 0.223307 & 0.994228 & 337.560 \\
\hline 0.08 & 0.223125 & 0.994159 & 337.582 \\
\hline
\end{tabular}

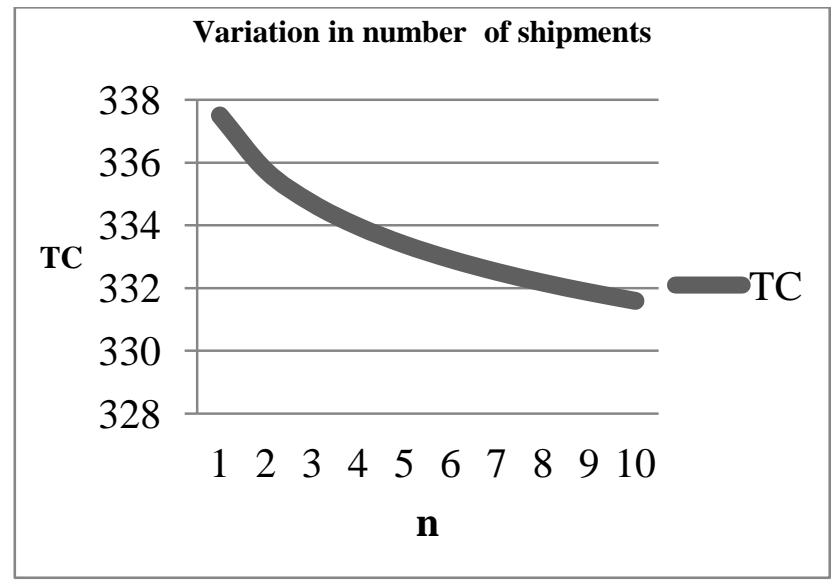

Fig.-1: Sensitivity graph w.r.to number of shipments ' $n$ ' and total cost

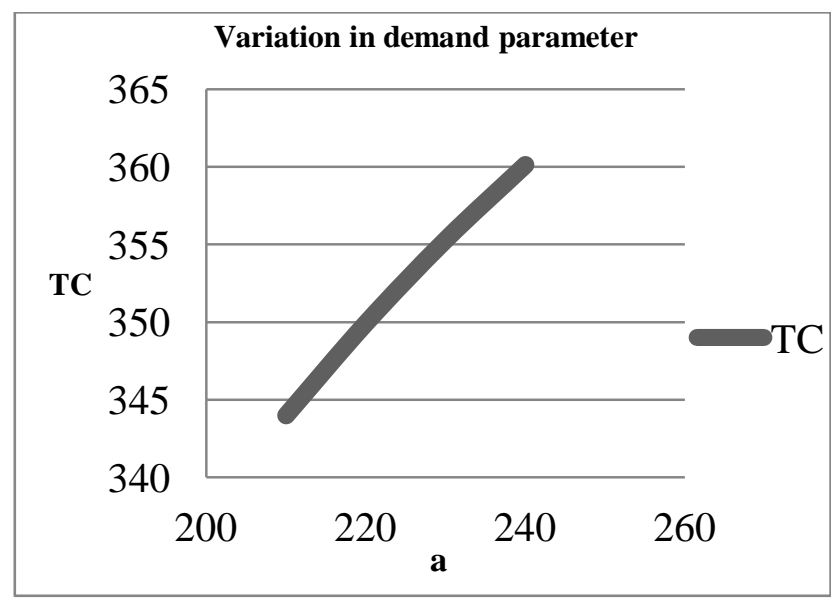

Fig.-2: Sensitivity graph w.r.to demand parameter 'a' and total cost
Variation in deterioration cost parameter

337.51

337.508

337.506

TC 337.504

337.502

337.5

337.498

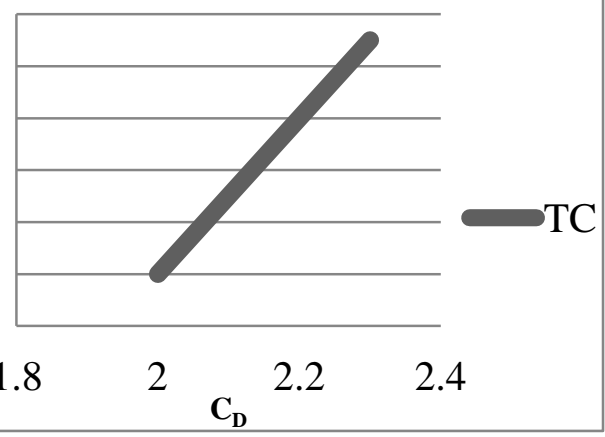

Fig.-3: Sensitivity graph w.r.to deterioration cost ' $C_{D}$ ' and total cost

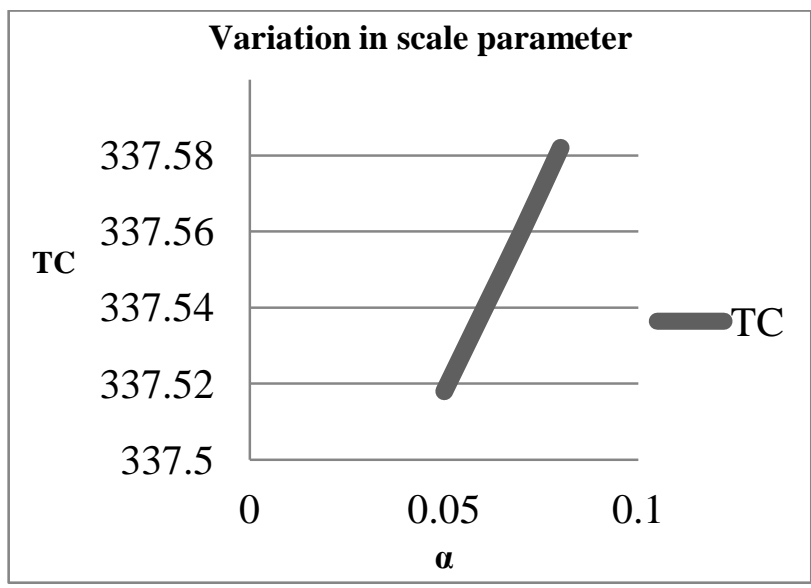

Fig.-4: Sensitivity graph w.r.to scale parameter ' $\alpha$ ' and total cost

\section{OBSERVATIONS}

- From table 1 / fig.1, as the number of shipments ' $n$ ' increases then the total cost decreases respectively.

- From table 2 / fig.2, if demand parameter ' $a$ ' increases then $t_{1}$ and $\mathrm{T}$ gradually decreases and the total cost increases respectively.

- From table 3/ fig.3, it is seen that deterioration cost ' $C_{D}$ ' increases then $t_{1}$ and $\mathrm{T}$ gradually reduces and the total cost slightly increases correspondingly.

- From table 4 / fig .4, it is seen that the scale parameter ' $\alpha$ ' increases then $t_{1}$ and $\mathrm{T}$ gradually decreases and the total cost slightly increases subsequently.

\section{CONCLUSION AND FUTURE RESEARCH}

Most of the researchers make assumptions that the deterioration starts from the instant of their arrival in the stock. But we developed a decaying inventory with noninstantaneous deterioration. The demand rate is quadratic function of time. These days we see that everywhere in every field high competition is available here we are talking about business of any organizations, manufacturer, shopping outlets, markets etc; because of that buyer has many different options to buy the things in different qualities with cheaper price. However as we analysis about competition we must know 
what to look for. It's not just copying others ideas we need to look for different strategy to compete the market. So, in order to develop customer's service and his revenue, organization concentrates to explore the opportunities in every direction. Manufacturers learn from each order quantity and lead time of buyer. Industry considers learning effect technique to cut down stock price and improve for higher profit in the business.

Also organizer's learning effect of holding cost for the different number of shipments as the number of shipments increases then total cost decreases. After arriving at the solution it becomes imperative to check the stability of the solution with respect to various system parameters. These parameters include different costs or the demand parameters. This model can be used in food related stuff, nuclear, chemical and pharmaceutical industries. These studies help to explore varying scenarios which ultimately aid in understanding and developing the inventory models.

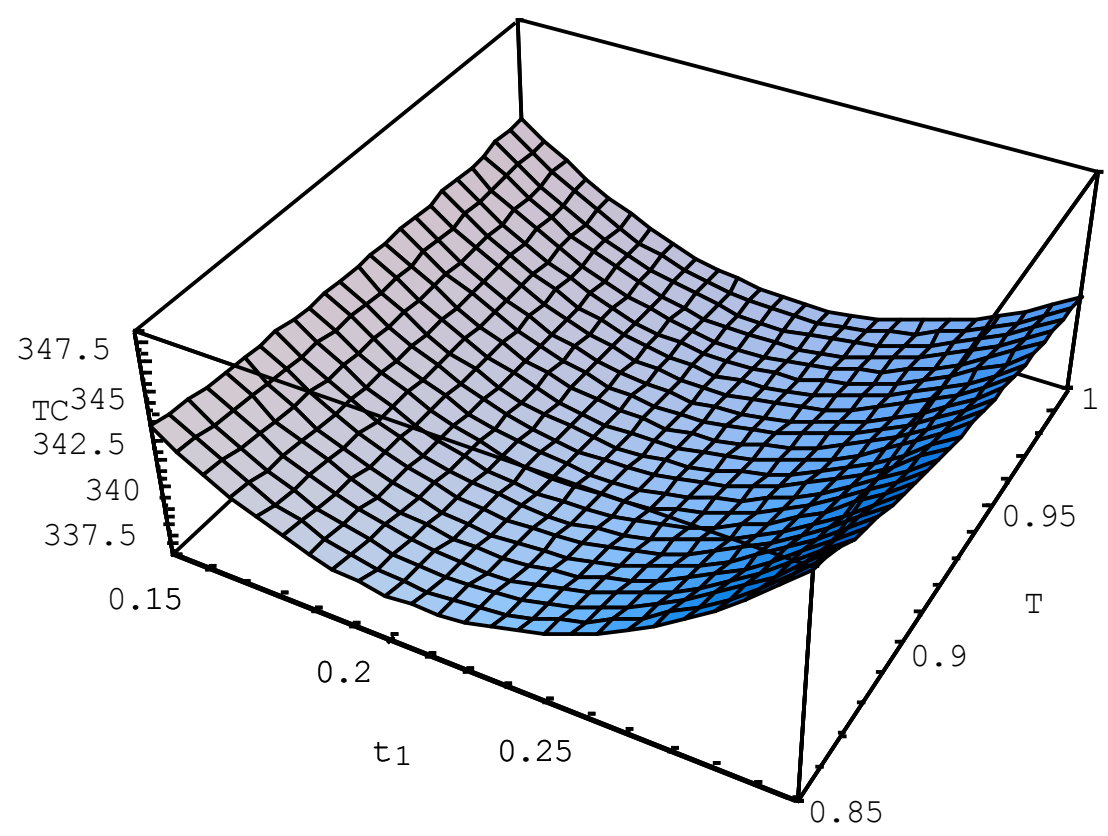

Fig.-5: Convexity of the proposed model with learning effect

\section{REFERENCES}

[1] Adler, G. L., \& Nanda, R. (1974). The effects of learning on optimal lot size determination-single product case. AIIE Transactions, 6(1), 14-20.

[2] Agarwal, A., \& Singh, S. R. (2013 ). An EOQ inventory model for two parameter Weibull deterioration with time dependent demand and shortages. International Journal of Engineering Research and Technology, 2(7).

[3] Anchal, A., Isha, S., \& Smita, R. (2016). A partial backlogging inventory model for non-instantaneous decaying items under trade credit financing facility. Indian Journal of Science and Technology, 9(34).

[4] Balkhi, Z. T. (2003). The effects of learning on the optimal production lot size for deteriorating and partially backordered items with time varying demand and deterioration rates. Applied Mathematical Modelling, 27(10), 763-779.

[5] Chang, H. J., \& Dye, C. Y. (1999). An EOQ model for deteriorating items with time varying demand and partial backlogging. Journal of the Operational Research Society, 50(11), 1176-1182.

[6] Chern, M. S., Yang, H. L., Teng, J. T., \& Papachristos, S. (2008). Partial backlogging inventory lot-size models for deteriorating items with fluctuating demand under inflation. European Journal of Operational Research, 191(1), 127-141.

[7] Covert, R. P., \& Philip, G. C. (1973). An EOQ model for items with Weibull distribution deterioration. AIIE transactions, 5(4), 323-326.

[8] Dye, C. Y. (2013). The effect of preservation technology investment on a non-instantaneous deteriorating inventory model. Omega, 41(5), 872-880.

[9] Fisk, J. C., \& Ballou, D. P. (1982). Production lot sizing under a learning effect. IIE Transactions, 14(4), 257-264.

[10] Ghare, P. M., \& Schrader, G. F. (1963). A model for exponentially decaying inventory. Journal of industrial Engineering, 14(5), 238-243.

[11] Goyal, S. K., \& Giri, B. C. (2001). Recent trends in modeling of deteriorating inventory. European Journal of operational research, 134(1), 1-16.

[12] Hariga, M. (1996). Optimal EOQ models for deteriorating items with time-varying demand. Journal of the Operational Research Society, 47(10), 1228-1246.

[13] Jaber, M. Y., Goyal, S. K., \& Imran, M. (2008). Economic production quantity model for items with imperfect quality subject to learning effects. International Journal of Production Economics, 115(1), 143-150. 
[14] Jaggi, C. (2014). An optimal replenishment policy for non instantaneous deteriorating items with price dependent demand and time-varying holding cost. International Scientific Journal on Science Engineering \& Technology, 17(03).

[15] Jordan, R.B.(1958), 'Learning how to use the learning curve', N.A.A. Bull, 39 (5), 27-39.

[16] Khanra, S., Mandal, B., \& Sarkar, B. (2013). An inventory model with time dependent demand and shortages under trade credit policy. Economic Modelling, 35, 349-355.

[17] Kumar, N., Singh, S. R., \& Kumari, R. (2013). Learning effect on an inventory model with two-level storage and partial backlogging under inflation. International Journal of Services and Operations Management, 16(1), 105-122.

[18] Mishra, S., Raju, L. K., Misra, U. K., \& Misra, G. (2011). An inventory model for deteriorating items with on-hand inventory dependent, variable type demand rate. International Journal of Mathematics \& Computation $^{\mathrm{TM}}$, 12(S11), 39-44

[19] Nahmias, S. (1982). Perishable inventory theory: A review. Operations research, 30(4), 680-708.

[20] Raafat, F. (1991). Survey of literature on continuously deteriorating inventory models. Journal of the Operational Research society, 42(1), 27-37.

[21] Sana, S. S. (2010). Optimal selling price and lot size with time varying deterioration and partial backlogging. Applied Mathematics and Computation, 217(1), 185-194.

[22] Sangal, I., Agarwal, A., \& Rani, S. (2016). A fuzzy environment inventory model with partial backlogging under learning effect. $T C, 14,1$.

[23] Sarkar, B., \& Moon, I. (2014). Improved quality, setup cost reduction, and variable backorder costs in an imperfect production process. International journal of production economics, 155, 204-213.

[24] Shukla, H., Shukla, V., \& Yadava, S. (2013). EOQ model for deteriorating items with exponential demand rate and shortages. Uncertain Supply Chain Management, 1(2), 67-76.

[25] Singh, S., Jain, S., \& Pareek, S. (2013). An imperfect quality items with learning and inflation under two limited storage capacity. International Journal of Industrial Engineering Computations, 4(4), 479-490.

[26] Tayal, S., Singh, S., \& Sharma, R. (2015). An inventory model for deteriorating items with seasonal products and an option of an alternative market. Uncertain Supply Chain Management, 3(1), 69-86.

[27] Widyadana, G. A., Cárdenas-Barrón, L. E., \& Wee, H. M. (2011). Economic order quantity model for deteriorating items with planned backorder level. Mathematical and Computer Modelling, 54(5), 1569-1575

[28] Wright, T. (1936). Factors affecting the cost of airplanes. Journal of Aeronautical Science, 3( 4), 122-128.

[29] Wu, K. S., Ouyang, L. Y., \& Yang, C. T. (2006). An optimal replenishment policy for non-instantaneous deteriorating items with stock-dependent demand and partial backlogging. International Journal of Production Economics, 101(2), 369-384.

[30] Yadav, D., Singh, S. R., \& Kumari, R. (2013). Inventory model with learning effect and imprecise market demand under screening error. Opsearch, 50(3), 418-432.

[31] Yelle, L. E. (1979). The learning curve: Historical review and comprehensive survey. Decision sciences, 10(2), 302-328.

\section{APPENDIX}

Total cost of the function from equation no.(15)

Where

$$
\begin{aligned}
& T C\left(t_{1}, T\right)=\frac{1}{T}\left[C+\left(h_{0}+\frac{h_{1}}{n^{\mu_{2}}}\right)\left[\frac{a}{2} t_{1}^{2}+\frac{b}{3} t_{1}^{3}+\frac{c}{4} t_{1}^{4}+\frac{a \alpha \beta}{\beta+1}\left\{\frac{(\beta+1)}{(\beta+2)} t_{d}^{\beta+2}+\frac{t_{1}^{\beta+2}}{(\beta+2)}-t_{1} t_{d}^{\beta+1}\right\}\right.\right. \\
& +\frac{b \alpha \beta}{2}\left\{\frac{t_{d}^{\beta+3}}{(\beta+3)}+\frac{4 t_{1}^{\beta+3}}{(\beta+1)(\beta+2)(\beta+3)}-\frac{t_{1}^{2} t_{d}^{\beta+1}}{(\beta+1)}\right\}+\frac{c \alpha \beta}{3}\left[\left\{\frac{t_{1}^{\beta+4}}{\beta(\beta+3)}\left\{3+\frac{\beta}{(\beta+4)}-\frac{(\beta+3)}{(\beta+1)}\right\}\right.\right. \\
& \left.\left.-\frac{t_{1}^{3} t_{d}^{\beta+3}}{(\beta+1)}+\frac{t_{d}^{\beta+4}}{(\beta+4)}\right\}\right]+C_{S}\left[\frac{a}{\delta} e^{\delta\left(t_{1}-T\right)}\left(t_{1}-T\right)+\frac{a}{\delta^{2}}\left(1-e^{\delta\left(t_{1}-T\right)}\right)+\frac{b}{\delta^{3}}(T \delta-2)+\right. \\
& \left.\frac{b}{\delta^{3}} e^{\delta\left(t_{1}-T\right)}\left\{\delta^{2} t_{1}\left(t_{1}-T\right)-\delta\left(t_{1}-T\right)-\delta t_{1}+2\right\}+\frac{c}{\delta^{4}}\left\{e^{\delta\left(t_{1}-T\right)}\left(4 \delta t_{1}-\delta^{2} t_{1}^{2}-6\right)+\delta T(\delta T-4)+6\right\}\right] \\
& +C_{D}\left[\frac{a \alpha}{(\beta+1)}\left\{t_{1}^{\beta+1}-t_{1} t_{d}^{\beta}(\beta+1)+\beta t_{d}^{\beta}\right\}+\frac{b \alpha}{(\beta+2)}\left\{t_{1}^{\beta+2}-\frac{t_{1}^{2} t_{d}^{\beta}}{2}(\beta+2)+\frac{\beta}{2} t_{d}^{\beta+2}\right\}+\right. \\
& \left.\frac{c \alpha}{(\beta+3)}\left\{t_{1}^{\beta+3}-\frac{t_{1}^{3} t_{d}^{\beta}}{3}(\beta+3)+\frac{\beta}{3} t_{d}^{\beta+3}\right\}\right]+C_{L}\left\{a\left(T-t_{1}\right)+\frac{b}{2}\left(T^{2}-t_{1}^{2}\right)-\frac{\left(a+b T+c T^{2}\right)}{\delta}\right. \\
& \left.\left.+\frac{c}{3}\left(T^{3}-t_{1}^{3}\right)+\frac{(b+2 c T)}{\delta^{2}}-\frac{2 c}{\delta^{3}}+e^{-\delta\left(T-t_{1}\right)}\left\{a+b t_{1}+c t_{1}^{2}-\frac{b}{\delta^{2}}-\frac{2 c t_{1}}{\delta^{2}}+\frac{2 c}{\delta^{3}}\right\}\right\}\right]
\end{aligned}
$$

